\title{
Effects of Computerized Simulation, Drill and Practice, and Tutorial Instructional Packages on Learning Outcomes of Fine-Arts Students in Nigerian Junior Secondary Schools
}

\author{
Lanre Idowu (Ph. D) \\ Faculty of Education, Obafemi Awolowo University, Ile-Ife
}

\begin{abstract}
It is the desire of every teacher to ensure effective and quality education performance. Fine-Arts is a practical oriented subject. In Nigeria, reports and findings shows that students are deficient in the area of practical especially graphics. Also, the attitudes of some parents towards the subject influence the choice of the subject. The aim of the study was to develop computerized simulation, Tutorial and Drill and Practice instructional packages for teaching Graphics, determine the relative effects of these packages on students' performance in Graphics,examine the effects of the packages in improving students' retention of concepts in Graphics, investigate the effects of these packages on students' attitude to Fine-Arts and investigate influence of sex on students' performance in Graphics. The study adopted the non-equivalent pretest, posttest control group design. The sample was made up of four intact classes of JSS III students in four schools from each of the four states mentioned above. The schools were purposively selected based on the availability of Fine-Arts studio. One intact class each was selected from the schools using simple random sampling technique. The schools were then assigned randomly to one control and three experimental groups. The study concluded that gender of the students did not have influence on the learning outcomes. In other words, the effectiveness of the treatment was not based on sex. It also concluded that the effectiveness of each of the treatment was not dependent on academic ability and finally that each of the three treatments were effective in improving students' performance.
\end{abstract}

Keywords: simulation, tutorial, drill-and-practice, gender, technology

DOI: $10.7176 / \mathrm{JEP} / 12-8-05$

Publication date:March $31^{\text {st }} 2021$

Introduction

In this age of technological advancement, mentioning technology generally inspires thoughts of advancement, improvement and progress. On the contrary, the lack of technology stirs feeling towards a practice as antiquated, ineffective and clumsy. The classroom has not been exempted from this general thinking.

In considering the use of any teaching style, educators will often use Benjamin Bloom's Taxonomy as a beginning point of planning. Certain principles of human cognitive learning are well established to be used by educators wanting to teach in ways most likely to produce learning. Three of these principles according to Joseph Lowman (2012) are that "It is better for students to be active seekers than passive recipients of learning; for students to be fully engaged in learning, their attention must be focused on the material; and students learn images as well as words, but images are more easily remembered. All these principles touch upon the use of technology in the classroom.

Barnabas (2005), noted that the Nigerian National Policy on Education regarding the teaching of Fine-Arts at all levels of education, is facing challenges of shortage of qualified Fine-Arts teachers. The policy also positions that teachers' quality affect students' performance. There is therefore a need for a deliberate and purposeful training of Fine-Arts teachers for the school system. As a result of shortage of trained teachers, some schools employed the services of teachers who are not professional artist. On account of this, students are exposed to poor methods of teaching. Consequent upon this defect, the performance of students in Fine-Arts at the secondary school level is adversely affected as Adeyanju, Aladejana and Idowu, (2008) and Owokade (2006) have found. The West African Examination Council's Chief Examiners Report, (2010) stated that students perform poorly and are deficient in the practical aspects like graphics.

The other problem area affecting Fine-Arts teaching is inadequate teaching facilities. Research in Fine-Arts has shown that most secondary schools in Osun State lack Fine-Arts materials and purposely-built Fine-Arts studios. Gofar, (2000); Ubangida, (2004); and Barnabas 2005, attest to this problem of lack of Fine-Arts materials and facilities. Adeyanju (1996) pointed out that in some cases; Fine-Arts studios were converted to office space. This is a serious cause for concern because if facilities are not available, the teaching of Fine-Arts is at best an exercise in futility. It is observed that student-artists cannot acquire artistic skills without the use of relevant FineArts materials for required practice. There is need for spacious environment for Fine-Arts Studio and make up laboratory.

Another problem of Fine-Arts teaching at the secondary school levels is the ambivalent negative attitude of the Nigerian society and government towards the subject. Government takes interest in funding the sciences. 
Awards and scholarship are often given to best students in the area of sciences. This brings discouragement to students who would have loved to offer it in secondary schools with the plan of being self-reliant in accordance to one of the objectives in the National Policy of Education.

Nigeria is in the age of computer and information technology that has ushered in a complete reformation of the schools' curriculum. Fine-Arts programmes also need curriculum review so as to make the curriculum richer. Specialists should therefore be given the opportunity to review the Fine-Arts curriculum. The Fine-Arts specialist is supposed to be expert in the use of computers because the production process in publishing is a herculean task. The artist manually illustrates the cover of text books and the text pages. The drawing preparation of layout and the typesetting that the compugraphic machine create makes works of publishing faster and easier, this is why curriculum review is necessary, as manual work will get reduced and more work will get done. Imagine the challenge of the artist pasting of large fonts for display functions, the tasks are difficult to achieve but computers have numerous typefaces and their corresponding characters are unlimited.

The use of letraset materials for display typography are expensive and scarce in the present decade but the computer has sufficient capacity to reduce the labour of the artist. The various stages of production in the FineArts discipline are indeed painstaking, time consuming and the end products are sometime inferior to what the computer can do.

\section{PROBLEM STATED/JUSTIFICATION}

The art of teaching is concerned with passing across ideas, knowledge, skills and modifying the behaviour of learners by teacher. But experience has shown that the use of spoken words (traditional approach) alone in the communication of ideas, knowledge, or skills in a way that affect learners is insufficient, ineffective and inefficient in producing the desired learning outcomes. The learning of Fine-Arts, which is a practical oriented subject, has been beset with serious problems and challenges. The reason for this could be ascribed to the fact that there are topics in Graphics that pose serious problems of comprehension to students. These topics cannot be taught effectively without the use of relevant instructional materials that would make learning practicable. Fine-Arts cannot be learned in isolation as its teaching requires interactions between teacher and students, students and students, and between students and materials.

In addition, the depth of contents to be covered in Fine-Arts discipline as a separate school subject in the curriculum are enormous for the number of periods allocated to it, as a result, of which the theoretical aspects are mostly emphasized, thereby neglecting the acquisition of necessary skills and practical experiences.

As a consequence of the above, learners perform poorly in examinations. The poor performance of students in Fine-Arts in the senior secondary schools' certificate has also generated serious concern among Fine-Arts teachers. The West African Examination Council (WAEC) (2013) reports, continually reveal that students face challenges in graphics as an aspect of Fine-Arts. This may be ascribed to the instructional strategy being used by teachers, which may not be effective. This attest to the need for experimenting with the three developed packages to test the modes of computer Drill and Practice, Simulation and Tutorial approaches to the teaching of Fine-Arts.

Aside the use of Fine-Arts products in the industrial setting is the use of the skill for preparing instructional materials for teaching. Mutebi and Matora (2004) have emphasized the effect of instructional materials utilization in teaching and learning. The author put it that it is easy to learn and remember $10 \%$ of what we hear, $40 \%$ of what we discuss with others and $80 \%$ of what is experienced directly or practiced. However, whether the use of instructional materials really influence students' learning outcome or whether teaching effectiveness become enhanced by the use of instructional materials are some of the variables of learning that needs investigation.

The ubiquity of the technology is clear, not only its availability in schools, but also in its permeation of everyday life. The reality of the situation, however, is that the teaching of Fine-Arts at the secondary school level has not been effectively implemented (Cornelius, 2004; Ubangida, 2005). This is evident in the "talk and chalk" method that the Fine Arts teachers still employ in teaching. In the Fine-Arts classroom, the use of traditional approach is viewed as invisible and imposing, at times; the method is an impenetrable barrier between student and the teacher. In order to break this barrier, it is considered that the design of instruction that will involve three modes of Computer-assisted instruction (CAI) could be used because of its interactive and instructional activities. The computer can be used to present instruction such that the learning that takes place can be further motivated through the combination of text, graphics, sound and video. The use of these media would remove inhibition in the performance of learners.

The state of Fine-Arts has for many years been a source of concern due to neglect. Uzoagba (2002), explains the situation, "if a proper understanding of Art education has been made and better instructions on arts followed in schools and colleges much would have been done to redeem the subject from the neglect it has always suffered in the society. It is apparent that few students offer Fine-Arts at the senior secondary and tertiary education levels because of its several challenges of its teaching without new approaches. Such situations seem to undermine FineArts teaching.

From a study that Lawson and Ajibade (2012) carried out, between 2006 - 2011, out of the 2,866 school 
graduates in a selected group of secondary schools, only 219 students took Fine-Arts subject. This is a clear indication of low interest of students' enrolment into the Fine-Arts discipline and this affects the labour market. Therefore, how to ensure effective Fine-Arts teaching to make it more attractive and productive in the Junior secondary schools constitute the focus of this research.

Lack of knowledge of improvisation in meeting the instructional needs is another problem found in schools. Even then where computers are available, they are not used to teach Fine-Arts because the teachers are unable to use them.

Adeyanju (2003) has posited that the traditional method of teaching Fine-Arts in secondary schools is faulty and new ways of making Fine-Arts learning attractive to young learners needed exploration. This is perhaps the reason why the suggest use of computers for Fine-Arts teaching is plausible.

The contemporary world is a witness to the effects of Information Age, and since the primary sources of content information is no longer teachers' lectures or textbooks controlled, but dependent upon how to find information and how to use information quickly, creatively, and cooperatively, Fine-Arts, supported by Computer capability may be an advantage.

Students of contemporary times are inundated with data, but are starving for meaningful learning. Fine-Arts knowledge and skills processed through the opportunities that the computer offers may be of great value to the Fine-Arts learner. Students need to be made great thinkers, skilful individuals, problem-solver, and creative worker. Fine-Arts processed through the computer programming can do this with very little effort.

Since the traditional approach to teaching is generally found lacking in meeting the observed needed values of Fine-Arts instruction, incorporation of Fine-Arts process through the three modes of Computer Assisted Instruction (CAI), drill and practice, simulation and tutorial need exploration. The Fine-Arts learners are deficient in the use of robust graphics skills in their studies. It is expected that the use of computer modes would stimulate further interest in Fine-Arts learning when the new approach is imbibed.

The CAI will be used to present drill and practice exercise, and tutorial to the Fine-Arts learners, and it will be organized to engage the students in meaningful instruction.

\section{OBJECTIVES}

The specific objectives of the study are to:

(a) develop computerized simulation, Tutorial and Drill and Practice instructional packages for teaching Graphics.

(b) determine the relative effects of these packages on students' performance in Graphics

(c) examine the effects of the packages in improving students' retention of concepts in Graphics

(d) investigate the effects of these packages on students' attitude to Fine-Arts.

(e) investigate influence of sex on students' performance in Graphics.

\section{LITERATURE REVIEW}

\section{Overview of Computer Assisted Instruction (CAI)}

A multiple-choice item scoring machine called teaching machine was invented in 1924 by Sidney Pressy. This teaching machine also allowed for self-instruction which could increase the efficiency of instruction. This invention gave birth to the idea of computer assisted instruction long before the birth of personal computers. The first electronic digital computer was invented by John Vincent Atanasoff and Clifford Berry in 1939. It was called the Atanasoff-Berry Computer (ABC). The ABC was followed by another famous early computer called the Electronic Numerical Integrator and Calculator (ENIAC). The ENIAC was commissioned by the U.S Department of Defence and it was completed in 1946. The first documented Instructional use of the computer was a computer driven flight simulator used to train pilots at military training institute, USA in 1950. The computer was used for the first time in school in 1959. It was the use of International Business Machine 650 (IBM 650) computer to teach binary arithmetic to New York City elementary school children. Then it was found that programmed instruction can be presented through computers and medium size minicomputers were used for imparting instruction to the students. (Roblyer \& Edwards, 2000; Bansal, 2002).

The intense development and research with mainframe-based computer networks in schools, colleges and universities peaked in the early and mid-1970's. Mainframe and mini computers by International Business Machine (IBM) Corporation, Computer Curriculum Corporation (CCC) and the Control Data Corporation (CDC) dominated the field of computing in education.

\section{Patrick Suppes the Pioneer of Computer Assisted Instruction}

The first Computer Curriculum Corporation (CCC) president, Professor Patrick Suppes led an extensive research and development efforts that earned him the honorary "Grandfather of Computer- Assisted Instruction." Suppes predicted that technology would transform education, primarily because he believed that advances in technology would permit delivery of individualized instruction to students of all ages in many subject areas. Suppes conducted 
experiments and set initial standards for CAI (Campbell, 2000; Roblyer \& Edward, 2000).

Government funded projects initiated by universities in collaboration with hardware manufacturer contributed a lot in the development of CAI. Programmed Logic for Automatic Teaching Operation (PLATO) and TimeShared Interactive Computer Controlled Information Television (TICCIT) are two major projects dominating the field of CAI in 1960's and 1970's. A brief account of these projects is as follows:

\section{Programmed Logic for Automatic Teaching Operations (PLATO)}

Don Bitzer, working at the University of Illinois in conjunction with Control Data Corporation (CDC) initiated an instructional system called Programmed Logic for Automatic Teaching Operations (PLATO). The PLATO system was designed to integrate text and graphics, and used to develop tutorial lessons and complete courses rather than just drill and practice lessons. CDC's president, William Noris, had almost a belief with a mission that PLATO would revolutionalize classroom practice. He channelled significant funding and personnel into the development of PLATO between 1965 and 1980. (Roblyer \& Edward, 2000; Allessi \& Trollip, 1991; Cambell 2000).

The PLATO was a mass of hundreds of tutorial, games, simulations and drill and practice programmes. Students accessed PLATO through main frames computers. In assessing achievement gains, PLATO was equal or superior to conventional classroom (Robyler \& Edward, 2000). Under National Science Foundation (NFC) founding PLATO courseware was produced for elementary school arithmetic and reading and for community college mathematics, English, Biology, Chemistry and Accounting.

\section{Mastery Learning Models}

Two more worth mentioning developments, parallel to the Time-Shared, Interactive, Computer-Controlled Information Television (TICCIT) were Programme for Learning in accordance with Need (PLAN), developed at the American Institute for Research and the Individually Prescribed Instruction (IPI) system to support mastery learning models with computer managed instruction systems. IPI focused on diagnosis and development of curriculum materials in reading and arithmetic (Roblyer \& Edwards, 2000).

In recent decades, Computer Assisted Instruction (CAI) has been increasingly used in schools to supplement conventional teaching approaches (Kulik \& Kulik, 1991; Sweller, 2008). Computer-assisted instruction has developed from limited drill and practice programs to more sophisticated learning systems with highly interactive and complex functions, including simulations and virtual laboratories (Bernard, Abrami, 2010; Slavin \& Lake, 2008). The developments in computer technology have also equally provided students with a broader range of learning opportunities that increased control over their learning (Bernard, Abrami, 2010).

Khirwadkar (1998) developed software for Chemistry teaching and further studied the effectiveness of CAI on student's achievement. Ranade (2001) worked on Science teaching through CAI and concluded that the use of CAI would lead to effective learning. When the packages were used in self-learning group, it served a better alternative to ineffective teaching.

Computer Education is perceived as a new instructional system that is designed to improve the quality of teaching and learning and to aid technological and socio-economic development. This statement was further corroborated by the former Federal Minister of Education, Professor Jubril Aminu in his address to the Ad-hoc Committee on computer Literacy in Nigeria, stating that the objectives of the nation's Computer Education programme, among other things, were to:

i.) bring about a computer literate society in Nigeria within a short space of time;

ii.) enable the present generation of school children at all levels, appreciate the potentials of the computer; and

iii.) enable learners to be able to use the computer in various works of life and later occupation.

With these laudable objectives, all the state governments in Nigeria had to follow the Federal Government policy and introduced Computer Education and Literacy in secondary schools as at 1997. The general objectives are to:

i.) bring about a computer literacy in each state in Nigeria;

ii.) develop the use of computer as teaching tool in all subject areas and

iii.) familiarize students with the use of computer technology;

iv) enable the present generation of school children at the secondary school level appreciate the potentials of the computer and be able to utilize the computer in various aspects of life and later occupation;

v) expose the teachers and the students to the latest scientific knowledge and skills.

From the foregoing, and based on the importance of computer to learning, it is felt that the introduction to the Nigerian educational system is a step in the right direction.

The incursion of the electronic computer system into the educational setting, according to Sherman (2005) provides the wherewithal to solve teaching and learning problems more accurately than hitherto conceived. Computer Assisted Instruction (CAI) is a program that this study considered as a form of instructional material presented by the mode of a computer system. 
Odunsi, (2001) and Okegbile (2003) report that computer application in educational processes contributes immensely to the teaching and learning process, and its electronic nature improves the quality and quantity of teaching techniques and learning modes. Arising from the attributes of the electronic media for which computer education should be made, one of the key areas of Fine-Arts implies therefore, that appropriate instructional materials are not just limited to charts and real objects alone but extend to other audio-visual instructional packages found useful in teaching.

Okwudishu (2005) discovers that the unavailability of computers in schools hampers teachers' use of the same, and where available, they are not being used. Lack of adequate search skills and of access points in the schools were reported as factors inhibiting the use of the Internet by secondary school teachers (Kaku, 2005). The absence of Information and Communication Technology (ICT) equipment in most Nigerian secondary schools leads students to resort to cybercafés for Internet access. Most cybercafé clients in Nigeria are students (Adomi, Okiy \& Ruteyan, 2003).

Aladejana (2013), in the years past, observed that classrooms situation was a cycle of memorisation, repetition, and note copying and these agreed perfectly to the world around the period, but now, the world is increasingly shaped by Information Communication Technology (ICT) and the efforts needs encouragements. It is known that children in the 21 st Century spend so much time watching cartoons on television, and also play games using ICT related tools. This is so, since Technology has become an integral part of our everyday lives; at home learners come in contact with mobile phones, television, computers, internet, games, cash registers, barcode, scanners, traffic lights, automatic doors, security cameras, remote controls, fax machines, the list can go on and on. The conflict then arises when such students get to the classroom and are still expected to listen, write and regurgitate, there is therefore a need to develop a self-learning material to make learning easy.

\section{Theoretical Framework}

The theoretical framework of this research is hinged on Constructivism. Constructivism is basically a theory -based on observation and scientific study -- about how people learn. It says that people construct their own understanding and knowledge of the world, through experiencing things and reflecting on those experiences. When we encounter something new, we have to reconcile it with our previous ideas and experience, maybe changing what we believe, or maybe discarding the new information as irrelevant. In any case, we are active creators of our own knowledge. To do this, we must ask questions, explore, and assess what we know.

In the classroom, the constructivist views of learning can point towards a number of different teaching practices. In the most general sense, it usually means encouraging students to use active techniques (experiments, real-world problem solving) to create more knowledge and then to reflect on and talk about what they are doing and how their understanding is changing. The teacher makes sure she understands the students' pre - existing conceptions, and guides the activity to address them and then build on them.

\section{Methodology}

Study Location:

The study was conducted in Osun, Oyo, Ogun and Edo States. These areas are well known for their artistic works. For instance, In Osogbo, Osun State, tie and dye is prominent. Oyo town in Oyo State is known for calabash carving, Abeokuta in Ogun State is well known for batik (-one method of dying) while Edo is known for bronze casting and other forms of art works. In all the States mentioned, there are higher institutions where Fine Arts is being offered, which gives hope to Secondary School students to further studies in this discipline. The higher Institutions include: Obafemi Awolowo University, Ile-Ife, St. Andrew's College of Education, Federal University of Agriculture and University of Benin respectively.

\section{Study Design}

The study adopted the non-equivalent pretest, posttest control group design. In non-equivalent design, intact class was used as the treatment and control groups. In one sense, it just means that assignment to group was not randomized. In this study, the researcher did not control the assignment to groups through the mechanism of random assignment.

\section{Sample and Sampling Technique:}

The sample was made up of four intact classes of JSS III students in four schools from each of the four states mentioned above. The schools were purposively selected based on the availability of Fine-Arts studio. One intact class each was selected from the schools using simple random sampling technique. The schools were then assigned randomly to one control and three experimental groups

\section{Research Instruments}

Three instruments were used for the study they include: Graphic Achievement Test (GAT) and a Questionnaire on attitude of students to Fine-Arts (QASF), The third instrument is the Revised Minnesota paper form Board Test 
(RMPFBT) used to classify students into low and high academic ability. The GAT adapted by the researcher consists of 20-test question items selected from Osun-State junior secondary school certificate examination (JSSCE) past question papers; all in objective items. The GAT was used for pre-test, post-test and retention tests. The QASF consists of 30 test questions structured in a five-point likert type scale response format questionnaire designed by the researcher and used to measure students' attitude towards graphics. The RMPBFT consists of twodimensional diagrams cut into separate parts in 64 multiple choice items. For each diagram, there are five figures with lines indicating the different shapes out of which they are made. From these, the subject chooses the one figure which is composed of the exact parts that are shown in the original diagram.

\section{Data Collection}

The researcher at different times administered the pretest on the four groups at the first meeting using the GAT. The groups include: Simulation group, Drill and Practice group, Tutorial group and the control group that will be exposed to teacher expository method. The scripts were marked and graded with a minimum of 20 marks. Mean scores from the four schools were calculated.

The first experimental group was taught using the computerized simulation with students in the group exposed to simulated software package of Corel Draw 12. The second experimental group was taught using the computerized drill and practice mode. Students in this group were exposed to a drill exercise in form of a quiz. The third experimental group was taught using the computerized tutorial mode such that students were exposed to a video and slides shows simultaneously. The control group was exposed to the teacher expository method of the talk and chalk method. Three instruments were used for data collection. These are: Graphic Achievement Test (GAT) which was administered as pretest, posttest and retention test; and Questionnaire on Attitude of Students to Fine-Arts (QASF) which was administered before and after treatments. The third was the Revised Minnesota paper form Board Test. (RMPFBT). The researcher had three instructional sessions per week for Twelve weeks. Data collected were analysed using appropriate descriptive and inferential statistics.

The RMPFBT was administered to identify students' academic ability for the purpose of categorizing them into low and high academic ability. This RMPBFT was used to assess the effectiveness of the instructional strategy based on the academic ability of the students.

The treatment started a week after the pretest. The period lasted for six months of six lessons per week of 45 minutes. This treatment was for each group, exposing each class to 18 lessons contact with the researcher.

Four classes were taught in all. The main characteristics of each instructional technique was explained to each group and detailed instructions spelt out. The post-test was conducted in the third month of the study in the four schools using GAT. Two weeks after the posttest, a retention test was also conducted.

\section{Variables in the study}

The variables in the study are:

a. The Independent variable: independent variable is the instructional strategies that were manipulated. The strategies used are: (I). Simulation Package (II) Tutorial Package (III) Drill and Practice Package.

b. The Dependent variable: Learning outcomes constitute the dependent variables. These are scores from pre-test and achievement of learners at the post-test.

\section{Experimental Intervention}

Instructional Package (A): Drill-and-practice software provided exercises in which students work with examples and receive feedback on the correctness of the test items.

The design of the drill and practice programme were in four steps:

1. The computer screen presents the student with questions on the principles and elements of design for their response.

2. The student responded by clicking the mouse;

3. The computer informs the student whether the answer is correct or wrong; and

4. If the student is right, the opportunity to move up to the higher problems to solve were given. When student's response is wrong, the computer will provide the correct answer automatically when the button is clicked.

Instructional Package (B):

The CAI simulation packaged learning material was used for the experimental Group 2 -

A simulation is a computerized model of a real or imagined system that is designed to teach how the system works.

The simulation exercise provides the learner with the essential elements of the real situation without hazards, cost or time constraints.

The use of simulation extends the experience of pupils and stimulates their learning interests. It also increases student's motivation and confidence. This is so because it allows repetition with variations unlike in real life. A 
simulation allows students repeat events continuously as they wish and with unlimited variations.

\section{Instructional Package (C):}

The CAI Tutorial Packaged learning material was used for experimental Group 3. The subject matter was taught by the package. Explanations were given orally through video and needed visuals presentation of slides and text. The computer re-acts to student's response by talking to him.

\section{Instructional Package (D):}

Learning material for control group: Conventional Expository Teaching Strategy. The school Fine-Arts teacher acted as learning facilitator and Posters and drawings were employed as demonstration material during the instructional activities. Chalk and Talk methods were employed. Students were not exposed to any treatment, but the same contents were taught as in other groups.

\section{Testing of Hypotheses}

Five hypotheses were generated and tested in the study. The results are presented below Hypothesis 1: There is no significant effect on the students' performance in graphics when exposed to the different strategies.

To test this hypothesis, the students' posttest performance scores in graphics were subjected to a test of between subject effect using Analysis of Covariance using different instructional packages as the differentiating variables and the pretest scores the covariates. The result is presented in table 1

Table 1: Tests of Between-Subjects Effects in students' performance across the instructional packages Dependent Variable: Post

\begin{tabular}{|l|r|r|r|r|r|}
\hline Source & Type III Sum of Squares & Df & Mean Square & F & Sig. \\
\hline Corrected Model & $136.324^{\mathrm{a}}$ & 3 & 45.441 & 4.990 & 003 \\
Intercept & 24066.921 & 1 & 24066.921 & 2642.598 & .000 \\
Grp & 136.324 & 3 & 45.441 & 4.990 & .003 \\
Error & 1302.343 & 143 & 9.107 & & \\
Total & 25559.000 & 147 & & & \\
Corrected Total & 1438.667 & 146 & & & \\
\hline
\end{tabular}

a. $\mathrm{R}$ Squared $=.095$ (Adjusted R Squared $=.076$ )

Table 1 presents the result of the test between subject effects in the performance scores of the students when exposed to the three instructional packages. It can be seen from this table that the F-value obtained in the test is 4.99 at p-value of 0.003 , since the p-value fails to attain the 0.05 threshold. Hence the hypothesis cannot be accepted and it can be concluded that there is a significant effect of the instructional packages on the performance of the students in Graphics.

In order to trace the relative effects of the instructional strategies a post hoc multiple comparison test was carried out on the post test scores via Turkey HSD and the result is presented in table 2

Table 2 Posthoc Mulitple comparison of students' postest scores

\begin{tabular}{|l|r|r|r|r|r|}
\hline Grp (J) Grp & \multicolumn{1}{|c|}{$\begin{array}{l}\text { Mean } \\
\text { Difference (1-J) }\end{array}$} & \multicolumn{1}{l|}{ Std. Error } & \multicolumn{2}{|c|}{ Sig. } & \multicolumn{2}{|c|}{ 95\% Confidence Interval } \\
\cline { 5 - 6 } & $-2.52237^{*}$ & .72938 & .004 & -4.4181 & -.6267 \\
Traditional & $-2.47678^{*}$ & .76009 & .008 & -4.4523 & -.5013 \\
Simulation Drill & -1.51494 & .74364 & .178 & -3.4477 & .4179 \\
Tutorial & $2.52237^{*}$ & .72938 & .004 & .6267 & 4.4181 \\
Simulation & .04559 & .75106 & 1.000 & -1.9065 & 1.9976 \\
Traditional Drill & 1.00743 & .73442 & .519 & -.9014 & 2.9162 \\
Tutorial & $2.47678^{*}$ & .76009 & .008 & .5013 & 4.4523 \\
Simulation & -.04559 & .75106 & 1.000 & -1.9976 & 1.9065 \\
Drill traditional & .96184 & .76492 & .591 & -1.0262 & 2.9499 \\
Tutorial & 1.51494 & .74364 & .179 & -.4179 & 3.4477 \\
Simulation & -1.00743 & .73442 & .519 & -2.9162 & .9014 \\
Tutorial traditional & -.96184 & .76492 & .591 & -2.9499 & 1.0262 \\
Drill & &
\end{tabular}

*• The mean difference is significant at the 0.05 level.

Table 2. presents the Post Hoc Multiple comparison test using Turkey HSD. It can be seen from the table that those students who were exposed to simulation seem to perform better than any other instructional package. Those exposed to simulation were significantly better than those exposed to drill (mean difference $=2.476, \mathrm{p}<.05$ ), they are also better than those exposed to the tutorial package (mean difference $1.515, \mathrm{p}<.05$ ) as well as those exposed to the traditional approach (mean difference $=2.522, \mathrm{p}<.05$ ). Although students exposed to other instructional strategies showed some difference among themselves, however, the p-values in all the cases were greater than 
0.05. Hence these differences are not significant. It can therefore be concluded that the simulate: instructional package is the best for enhancing the performance of learners in graphics Other packages may be useful, however, no significant difference was found comparing learners exposed to them and those exposed to traditional instruction. method.

Hypothesis 2: There is no significant effect of improved retention of concepts in graphics when exposed to the different instructional strategies.

To test this hypothesis, the students' retention scores in graphics were subjected to a Test of between subject effect using Analysis of Covariance using the different instructional packages as the differentiating variables and the pretest scores as the covariates. The result is presented in table 3

Table3.: Tests of Between-Subjects Effects in students' retention across the three instructional packages Dependent Variable: Retention

\begin{tabular}{|l|r|r|r|r|r|}
\hline Source & Type III Sum of Squares & Df & Mean Square & F & Sign \\
\hline Corrected Model & $75.692^{\mathrm{a}}$ & 3 & 25.231 & 3.497 & .017 \\
Intercept & 24229.364 & 1 & 24229.364 & 3358.03 & 0.00 \\
Grp & 75.692 & 3 & 25.231 & 3.497 & .017 \\
Error & 1039.010 & 144 & 7.215 & & \\
Total & 25404.000 & 148 & & & \\
Corrected & 1114.703 & 147 & & & \\
Total & & & & \\
\hline
\end{tabular}

a. $\mathrm{R}$ Squared $=.068$ (Adjusted R Squared .048)

Table 3 presents the result of the test between subject effects in the retention scores of the students when exposed to the three instructional packages. It can be seen from the table that the F-value obtained in the test is 3.497 at p-value of 0.017 . Since the p-value is less than the 0.05 threshold, the hypothesis cannot be accepted and it can be concluded that there is a significant effect of the instructional packages on the retention of concept among the students in Graphics.

In order to trace the relative effects of the instructional strategies a post hoc multiple comparison test was carried out on the post test scores via Tukey

HSD and the result is presented in table 4

Table. 4.. Posthoc Multiple comparison of students' retention scores

\begin{tabular}{|ll|r|r|r|r|r|}
\hline (1) Grp & (J) Grp & Means Difference (1-J) & Std. Error & \multicolumn{1}{l|}{ Sig. } & \multicolumn{2}{|c|}{ 95\% Confidence Interval } \\
\cline { 5 - 7 } & & & & & Lower Bound & Upper Bound \\
\hline \multirow{4}{*}{ Simulation } & traditional & $-1.59527^{*}$ & .61269 & 0.49 & -3.1878 & -.0027 \\
& Drill & $-1.85851^{*}$ & .63814 & .021 & -3.5172 & -.1998 \\
& Tutorial & -.89189 & .62451 & .484 & -2.5152 & .7314 \\
& - Simulation & $1.59527^{*}$ & .61269 & .049 & .0027 & 3.1878 \\
& -.26324 & .62658 & .975 & -1.8919 & 1.3645 \\
Traditional & Drill & .70338 & .61269 & .660 & -.8982 & 2.2959 \\
& Tutorial & $1.85851^{*}$ & .63814 & .021 & .1998 & 3.5172 \\
& Simulation & .26324 & .62658 & .021 & -1.3654 & 1.8919 \\
& Traditional & .96661 & .63814 & .431 & -.6921 & 2.6253 \\
& Tutorial & .89189 & .62451 & .484 & -.7314 & 2.5152 \\
& Simulation & -.70338 & .61269 & .660 & -2.2959 & .8892 \\
& Traditional & -.96661 & .63814 & .431 & -2.6253 & .6921 \\
\hline
\end{tabular}

The mean difference is significant at the 0.05 level.

Table 4. presents the Post Hoc Multiple comparison test on the students' retention score using Turkey HSD. It can be seen from the table that those students who were exposed to Drill instructional package seem to retain more graphics concept than any other instructional package. Those exposed to drill instructional packages were significant: better in retention of graphics concept than those exposed to simulation (mean difference $=1.858, p<$ $.05)$, they are also better than those exposed to other instructional packages; however, the p-values in all the cases were greater than 0.05 . Hence these differences are not significant. It can therefore be concluded that the drill instructional package is: best for enhancing the performance retention of concepts in graphics. Other packages may be useful; however, no significant difference was found in comparing learners exposed to them and those exposed to traditional instructional method

Hypotheis3: There is no significant influence of sex on students' performance in graphics when taught using the different packages

To test this hypothesis. the students' performance scores in graphics were subjected to a test of between subject effect via Analysis of Covariance using the different instructional packages as the differentiating variables, sex as the interacting variable and the pretest scores as the covariates. The result is presented in table 5

Table 5: Tests of Between-Subjects Effects of influence of sex on students' performance 
Dependent Variable: Post

\begin{tabular}{|l|r|r|r|r|r|}
\hline Source & Type III Sum of Squares & Df & Mean Square & F & Sig. \\
\hline Corrected & $208.542^{\mathrm{a}}$ & 8 & 26.068 & 2.807 & .006 \\
Model & & & & & \\
Intercept & 7946.976 & 1 & 7946.976 & 855.837 & .000 \\
Grp * Sex & 208.542 & 8 & 26.068 & 2.807 & .006 \\
Error & 1290.701 & 139 & 9.286 & & \\
Total & 25584.000 & 148 & & & \\
Corrected & 1499.243 & 147 & & & \\
Total & & & & & \\
\hline
\end{tabular}

a. R Squared $=.139$ (Adjusted R Squared $=.090$ )

Table. .5. shows the test of influence of sex on students' performance in graphics when taught using the different packages. It can be seen from the table that the p-value obtained on the test of influence of the interaction between sex and experimental group is 2.807 at $\mathrm{p}=0.006$. since the $\mathrm{p}$-value is less than 0.05 , the hypothesis can no longer be accepted. It can therefore be concluded that there is a significant effect of sex on the students' performance in graphics across the different instructional packages. This can be better under stood through the table of estimated Marginal mean scores as presented in table

Table of estimated Marginal mean scores

\begin{tabular}{|c|c|c|c|c|c|}
\hline \multicolumn{6}{|c|}{ Grp * Sex } \\
\hline \multicolumn{6}{|c|}{ Dependent Variable: Post } \\
\hline \multirow[t]{2}{*}{ Grp } & \multirow[t]{2}{*}{ Sex } & \multirow[t]{2}{*}{ Mean } & \multirow[t]{2}{*}{ Std. Error } & \multicolumn{2}{|c|}{ 95\% Confidence Interval } \\
\hline & & & & Lower Bound & Upper Bound \\
\hline \multirow[t]{2}{*}{ Simulation } & Male & 11.200 & .787 & 9.644 & 12.756 \\
\hline & Female & 11.455 & .650 & 10.170 & 122.739 \\
\hline \multirow[t]{2}{*}{ Traditional } & Male & 13.937 & .762 & 12.431 & 15.444 \\
\hline & Female & 12.812 & .762 & 11.306 & 14.319 \\
\hline \multirow[t]{2}{*}{ Drill } & Male & 12.812 & .762 & 11.306 & 14.319 \\
\hline & Female & 14.167 & .718 & 12.747 & 15.587 \\
\hline \multirow[t]{2}{*}{ Tutorial } & Male & 12.200 & .787 & 10.644 & 13.756 \\
\hline & Female & 13.190 & .665 & 11.876 & 14.505 \\
\hline
\end{tabular}

Table. . .6. shows the estimated marginal mean scores of students across the instruction packages groups and the sex groups. It can be seen that female students performed better than their male counterparts across all the instructional packages except in the traditional method.

Hypothesis 4: There is no significant influence of academic ability on students' performance in graphics when exposed to the different instructional strategies.

To test this hypothesis, the students' academic ability was determined using the MPFBT scores. The minimum score obtained was 12 while the highest score was 59. Any participant that scored lower than 24 (lower than approx. $40 \%$ ) is regarded as having an academic ability and when they scored $26(40 \%)$ to $3660 \%)$ they were regarded as having moderate academic ability and higher than $36(60 \%)$ they are said to possess high academic ability. The students' performance scores in graphics were then subjected to a test of between subject effect via Analysis of Covariance using the different instructional packages as the differentiating variables, academic ability as the interacting variable and the pretest scores as the covariates. The result is presented in table 7

Table 7.: Tests of Between-Subjects Effects of influence of sex on students' performance Tests of BetweenSubjects Effects

Dependent Variable: Post

\begin{tabular}{|l|r|r|r|r|r|}
\hline Source & Type III Sum of Squares & Df & Mean Square & F & Sig. \\
\hline Corrected Model & $797.999^{\mathrm{a}}$ & 11 & 72.545 & 13.978 & .000 \\
\hline Intercept & 17301.087 & 1 & 17301.087 & 3333.45 & .000 \\
\hline Grp* Acadg & 797.999 & 11 & 72.545 & 8 & .000 \\
\hline Error & 700.668 & 135 & 5.190 & 13.978 & \\
\hline Total & 25440.000 & 147 & & & \\
\hline Corrected Total & 1498.667 & 146 & & & \\
\hline
\end{tabular}

a. R Squared $=.532$ (Adjusted R Squared .494)

Table 7 shows the test of influence of academic ability on students' performance in graphics when taught using the different packages. It can be seen from the table that the p-value obtained in the test of influence of the interaction between academic ability and experimental group is 13.978 at p 0.000 . Since the p-value is less than 0.05 , the hypothesis can no longer be accepted. It can therefore be concluded that there is a significant effect of academic ability on the students' performance in graphics across the different instructional packages. This can be 
better understood through the table estimated Marginal mean scores as presented in table 8 Table of estimated Magina1 mean scores

\begin{tabular}{|c|c|c|c|c|c|}
\hline & & Acad & Grp & & \\
\hline Dependent V & le: Post & & & & \\
\hline Acadg & Grp & Mean & Std. Error & $95 \%$ Confidenc & nterval \\
\hline & & & & Lower Bound & Upper Bound \\
\hline & Simulation & 7.667 & .759 & 6.165 & 9.169 \\
\hline & Traditional & 6.400 & 1.019 & 4.385 & 8.415 \\
\hline Low & Drill & 12.333 & .759 & 10.831 & 13.835 \\
\hline & Tutorial & 11.176 & .553 & 10.084 & 12.269 \\
\hline & Simulation & 10.692 & .632 & 9.443 & 11.942 \\
\hline Moderate & Traditional & 13.375 & .805 & 11.782 & 14.968 \\
\hline & Drill & 13.167 & .930 & 11.327 & 15.006 \\
\hline & Tutorial & 12.125 & .805 & 10.532 & 13.718 \\
\hline & Simulation & 14.286 & .609 & 13.082 & 15.490 \\
\hline High & Traditional & 14.963 & .438 & 14.096 & 15.830 \\
\hline & Drill & 14.211 & .523 & 13.177 & 15.244 \\
\hline & Tutorial & 14.833 & .658 & 13.533 & 16.134 \\
\hline
\end{tabular}

Table 8....shows the estimated marginal mean scores of students across the instructional packages group and the academic ability groups. It can be seen that students having high level of academic ability performed better than their counterparts across all the instructional packages and in other levels of academic ability groups.

Hypothesis 5: There is no significant influence in the post attitudinal scores of students when exposed to the different instructional strategies.

To test this hypothesis, the students' attitudinal scores were subjected to a test of between subject effect via Analysis of Covariance using the different instructional packages as the differentiating variables and the pretest scores as the covariates.

The result is presented in table 9

\section{Tests of Between-Subjects Effects}

Dependent Variable: AttPost (Post Attitudinal)

\begin{tabular}{|l|r|r|r|r|r|}
\hline Source & Type III Sum of Squares & Df & Mean Square & F & Sig. \\
\hline Corrected Model & $12889.488^{\mathrm{a}}$ & 4 & 3222.372 & 50.826 & .000 \\
\hline Intercept & 1666.108 & 1 & 1666.108 & 26.279 & .000 \\
\hline AtrtPre & 9856.479 & 1 & 9856.479 & 155.464 & .000 \\
\hline Grp & 202.916 & 3 & 67.639 & 1.067 & .365 \\
\hline Error & 9066.242 & 143 & 63.400 & & \\
\hline Total & 1857026.000 & 148 & & & \\
\hline Corrected Total & 21955.730 & 147 & & & \\
\hline
\end{tabular}

a. $\mathrm{R}$ Squared $=.587$ (Adjusted R Squared $=.576$ )

Table 9 shows the test of significant difference in students' attitude toward graphics when taught using the different packages. It can be seen from the table that the $p$-value obtained on the test is 1.067 at $p=0.365$. since the $\mathrm{p}$-value is greater than 0.05 , the hypothesis can no longer be rejected. It can therefore be concluded that there is no significant difference in students' attitude toward graphics across the different instructional packages.

\section{Conclusion}

The following conclusions were drawn from the findings of this study among others:

1. Gender of the students did not have influence on the learning outcomes. In other words, the effectiveness of the treatment was not based on sex.

2. The effectiveness of each of the treatment was not dependent on academic ability.

3. Each of the three treatments were effective in improving students' performance

\section{Recommendations}

The following recommendations were drawn from the findings of this study:

1. Teacher should be encouraged to integrate computer in their daily classroom process

2. The Government and non-government agencies should equip both urban and rural schools with computers and new technologies for easy access by both teachers and students.

3. The government through the ministry of education should make fund available to schools to have eclassrooms and equip the same with recent educational media, like the three packages developed for this study 
4. Teachers should be given free and compulsory computer training to enable them use the new technology when supplied

5. Students in the faculty of education should be made to take courses in educational technology at all levels. This will enable them to develop and design packages for instructions especially in a time of pandemic like this.

6. A media resource centre should be established at local government's public library to see to the storage and maintenance of the educational materials

\section{References}

Adeyanju, J. L (2003) Teachers' Perception of the effects and use of learning aids in teaching. http://ultibase.rmt.edu.au/articles/nov03/adeyanju1.htm

Adeyanju, J.L. (1996): Effects of repetition of audio-taped instruction and cued visuals on acquisition of cognition imagery skilled of secondary school art students in Ile-Ife.

Unpublished PhD Thesis, Department of Educational Technology, OAU, Ile-Ife.

Adeyanju, J. L, Aladejana F. O, \& Idowu L, (2008). Towards a technology - oriented classroom: The use of computer graphic package. Proceedings of the Paris International Conference on Education, Economy and Society-Paris 17-19 July 2008.

Adomi, E.E., Okiy, R.B., \& Ruteyan, J.O. (2003). A Survey of cybercafés in Delta State, Nigeria. The Electronic Library 21 (5): 487-95.

Ajibade, B. \& I. Lawson (2011). "The limitations of teaching and learning Fine and Applied Arts at tertiary level in Cross River State," Global Journal of Educational Research, 2(1\&2), 27-32

Aladejana, F.O. (2013). Best educational practice as a panacea to educational conflicts in Nigeria, Keynote address presented at the 4th Annual Conference of the Faculty of Education, Adeyemi College of Education, Ondo.

Alessi, R. D. \& Trollip, S. R. (1991). Computer Based Instruction Methods and Development. Englewood:N.J; Prentice-Hall.

Bansal, S.K. (2002). Fundamentals of Information Technology. New Delhi: A.P.H. Publishing Corporation.

Barnabas, S. D. (2005). Teachers' assessment of children creative artwork: Case study of some primary schools in Kaduna State. Unpublished M. A. Thesis, Department of Fine Arts, A. B. U., Zaria.

Bernard, R. M., Abrami, P. C. (2010). A systematic review of the differential effects of teacher-centered and student-centered pedagogy in $\mathrm{K}-12$ science and mathematics.

Grant application submitted for funding to the Institute of Educational Sciences, Washington, DC.

Campbell J.P. (2000) A Comparison of Computerized and Traditional Instruction in the area of Elementary reading. Online Doctoral Dissertation. The University of Alabama.

CBSA: Content-Based soft annotation for multimodal image retrieval using Bayes point machines. IEEE Transactions on Circuits and Systems for Video Technology, 13(1), 26-38. (2003)

Federal Republic of Nigeria (2004). National Policy on Education, 4 th edition. NERDC Press. Yaba, Lagos Nigeria.

Gofar, D. N. (2000). Measurement of the relationship between continuous assessment score and performance in art. Unpublished M. A. Thesis, Department of Fine Arts, A. B. U., Zaria.

Joseph, L. (2012). Mastering the techniques of teaching San Francisco. Change: The Magazine of higher learning. 16(6) $51-52$

Kaku, F.A. (2005). The use of Internet by secondary school teachers in the rural areas of Delta State: The case of Udu Local Government Area. Abraka: Delta State University. Unpublished B.Sc. (LIS) project.

Kulik, J. A., \& Kulik, C. C. (1991). Computer based instruction what 200 evaluations say, paper presented at the annual convention of the association for educational communications and technology, Atlanta, A. (ED 285 521).

Khirwadkar, A. (1998). Development of Computer software for learning chemistry at standard XI.Vadodara: CASE, The M.S.University of Baroda, India: An unpublished Ph.D, Thesis.

Mutebi, M. and Matora, Y. (2004) ASESP students Curriculum and teaching resources book for Africa. Nairobi: ASESP. National Policy on Education (revised.), Lagos, NERDC

Odunsi, C.O. (2001). Computer and society. Lagos. University Press.

Okegbile, F.O. (2003). Computer aided learning. Central Education. 2 (3) 10-14.

Okwudishu, C.H. (2005). Awareness and use of Information and Communication

Owokade, O.O (2006). Facilitating Effective Performance of Students in Mathematics, Science and Technology in Secondary Schools. Paper presented at the FGN UNESCO Workshop for Inspectors, University of Lagos, Lagos, Nigeria

Ranade, M.D. (2006) Development of CAI Presentations for Science Teaching and Overview of Research Findings. International Journal of Science \& Math Education, Online First, Springer Netherlands. http://www.springerlink.com/content/m714216p73774834/fulltext.pd 
Roblyer, M.D. \& Edwards J. (2000). Integrating Educational Technology into Teaching, (Second Edition) Upper Saddle River: Prentice Hall Inc.

Slavin, R. E., \& Lake, C. (2008). Effective programs in elementary mathematics: A best evidence synthesis. Review of Educational Research, 78(3), 427-455.

Sweller, J. (2008). Human Cognitive Architecture. In M. Spector, D. Merrill, J. Van Merrienboer \& M. Driscoll (Eds.), Handbook of research on educational communications and technology (3rd ed., pp. 369-381). New York, NY:

Ubangida, M. B. (2004). An evaluation of art programm in some selected secondary schools in Taraba. Unpublished M. A. Thesis. Department of Fine Arts ABU Zaria 